\title{
TRIPPD: A Practice-Based Network Effec- tiveness Study of Postpartum Depression Screening and Management
}

Barbara P. Yawn, MD, MSc ${ }^{1}$

Allen J. Dietrich, $M D^{2}$

Peter Wollan, $\mathrm{PbD}^{1}$

Susan Bertram, MSN ${ }^{1}$

Debbie Grabam, MSPH

Jessica Huff, MPH, MS

Margary Kurland, $\mathrm{RN}^{1}$

Suzanne Madison, $\mathrm{MPH}^{1}$

Wilson D. Pace, $M D^{3}$

In collaboration with the TRIPPD practices

'Olmsted Medical Center, Department of Research, Rochester, Minnesota

${ }^{2}$ Dartmouth Medical Center, Dartmouth, New Hampshire

${ }^{3}$ National Research Network, American Academy of Family Physicians, Leawood, Kansas

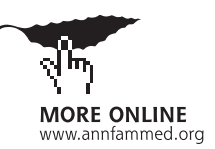

Conflicts of interest: authors report none.

\section{CORRESPONDING AUTHOR}

Barbara Yawn, MD, MSc

Research Department

Olmsted Medical Center

210 Ninth St SE

Rochester, MN 55904

byawn@olmmed.org

\begin{abstract}
PURPOSE Postpartum depression is common but inadequately recognized and undertreated. Continuing depressive symptoms are associated with adverse outcomes for the woman, her infant, and family. We wanted to determine the effect of a practice-based training program for screening, diagnosis, and management of depression in postpartum mothers.
\end{abstract}

METHODS In this practice-based effectiveness study, 28 practices were randomized to usual care $(n=14)$ or intervention $(n=14)$, and 2,343 women were enrolled between 5 and 12 weeks' postpartum. The intervention sites received education and tools for postpartum depression screening, diagnosis, initiation of therapy, and follow-up within their practices. Usual-care practices received a 30-minute presentation about postpartum depression. Screening information for the usual care was obtained from baseline surveys sent directly to the central site but was not available for patient care. Outcomes were based on patient-reported outcomes (level of depressive symptoms) from surveys at 6 and 12 months, plus medical record review (diagnosis and therapy initiation).

RESULTS Among the 2,343 women enrolled, 1,897 (80.1\%) provided outcome information, and were included in the analysis. Overall, 654 (34.5\% of 1,897) women had elevated screening scores indicative of depression, with comparable rates in the intervention and usual-care groups. Among the 654 women with elevated postpartum depression screening scores, those in the intervention practices were more likely to receive a diagnosis $(P=.0006)$ and therapy for postpartum depression $(P=.002)$. They also had lower depressive symptom levels at 6 $(P=.07)$ and 12 months' $(P=.001)$ postpartum.

CONCLUSIONS Primary care-based screening, diagnosis, and management improved mother's depression outcomes at 12 months. This practical approach could be implemented widely with modest resources.

Ann Fam Med 2012;10:320-329. doi:10.1370/afm.1418.

\section{INTRODUCTION}

$\mathrm{M}$ aternal postpartum depression is common but often goes unrecognized or undertreated in clinical practice. Postpartum depression adversely affects new mothers, infants, and young families. ${ }^{1.7}$ Initial attempts to improve recognition of postpartum depression included programs that provided universal screening in primary care offices and hospitals; these efforts increased identification, but outcomes were not assessed or not improved. ${ }^{8-13}$ More recent studies of screening for postpartum depression included referral to a mental health site for evaluation and care, but none have reported improved outcomes. ${ }^{14-17}$ These results prevented the American College of Obstetrics and Gynecology, the US Preventive Services Task Force, and the UK National Health Service's National Institute for Health and Clinical Excellence and Scottish Inter- 
collegiate Guideline Network from recommending for or against specific universal screening for postpartum depression because of lack of evidence. ${ }^{18-21}$

This effectiveness study reports on the comparison of 6- and 12-month maternal outcomes after the introduction of a practice-wide intervention consisting of postpartum depression screening, evaluation, and management based in family medicine offices compared with usual-care outcomes. The intervention was specifically designed to maintain most of the care within the local practice, reserving referral for complicated cases or unresponsive depression.

\section{METHODS}

\section{Study Design}

The Translating Research into Practice for Postpartum Depression (TRIPPD) effectiveness study was conducted in 28 family medicine research network practices $^{22}$ in 21 states between March 1, 2006, and August 31,2010 . Because the intervention involved changes in care at the practice level, randomization was done by practice. It was further stratified by residency vs nonresidency practice, rather than at the patient level, to prevent contamination across groups if both intervention and usual care were attempted within the same practice. The usual-care sites continued to provide the same postpartum and mental health care or referral as before study inception. After 24 months the usual-care sites were crossed over to the intervention; outcomes include women enrolled after the usual-care sites crossed over. Institutional review board approvals were obtained for each site. Eligible family medicine practices had to have provided maternity or well-baby care to more than 30 individuals in the previous year and to not be routinely screening for postpartum depression. Eligible women spoke English or Spanish, were aged at least 18 years, were 5 to 12 weeks' postpartum, and were receiving continuing care at the family medicine practice where they enrolled. Teenage mothers were excluded because of varying state legal requirements for age of research consent. Informed consent was obtained from all participating mothers.

\section{Intervention}

Intervention office staff members received training for a multistep postpartum depression screening and diagnosis process ${ }^{23}$ using the Edinburgh Postnatal Depression Scale (EPDS) ${ }^{24}$ and the 9-item Patient Health Questionnaire (PHQ-9). ${ }^{25}$ The multistep screening and diagnosis process allowed the use of the PHQ-9, a more-specific assessment for major depressive disorder for women identified as possibly depressed by the lessspecific EPDS. The PHQ-9 and physician evaluation were used in place of the Structured Clinical Interview for the Diagnostic and Statistical Manual of Mental Disorders (SCID) assessments. A PHQ-9 score of 10 or greater was considered consistent with postpartum depression if no other cause for the depressive symptoms was found by the evaluating primary care physician (PHQ-9 is scored on a range from 0 to 27, where higher scores indicate greater depression severity). If the EPDS was greater than 10 (scored on a scale from 0 to 30 , with a score of 10 or greater indicating possible depression), but the PHQ-9 was not elevated, the physician was directed to use clinical judgment regarding further evaluation and follow-up.

Each intervention practice was provided a set of tools to facilitate diagnosis, follow-up, and management of postpartum depression, which is summarized in Figure 1. (Tools are available in the Supplemental Appendix, available at http://annfammed.org/ content/10/4/320/suppl/DC1). The tools included an outline for the content of follow-up postpartum depression visits, including repeated use of the PHQ-9 to help determine response to therapy, ${ }_{1}^{26}$ and a written format for nursing follow-up telephone calls that dealt with medication initiation, adherence, and side effects. Selection, modification, and follow-up of specific types of therapy were left to the discretion of the physician and patient, with the support tools to describe common side effects and usual dose range for medications and an explanation of cognitive behavioral therapy.

\section{Study Protocol}

Practices enrolled the women, provided them the survey packets, which contained the EPDS and PHQ-9 screening questionnaires and a stamped return envelope, and then continued with care of the women depending on the site's randomization status. The EPDS and PHQ-9 screening questionnaires were included in the baseline survey packet for all women because the 2-step progressive assessment was not feasible for the usual-care group, and the data were crucial for outcome analyses. All further study-related contact with the women was done by the central study site, eg, sending women survey packets (as described above) at 6 and 12 months' postpartum for self-reported outcomes. Both usual-care and intervention patients completed and mailed the questionnaires directly to the central site at baseline and at 6 and 12 months' postpartum.

The intervention sites had routine access to the woman's EPDS and PHQ-9 screening score(s), but the usual-care sites did not. By including the EPDS and PHQ-9 in the survey packets, all women were queried about suicidal ideation. The central site was required to notify the woman's practice immediately whenever 


\section{Figure 1. Postpartum depression assessment and follow-up.}

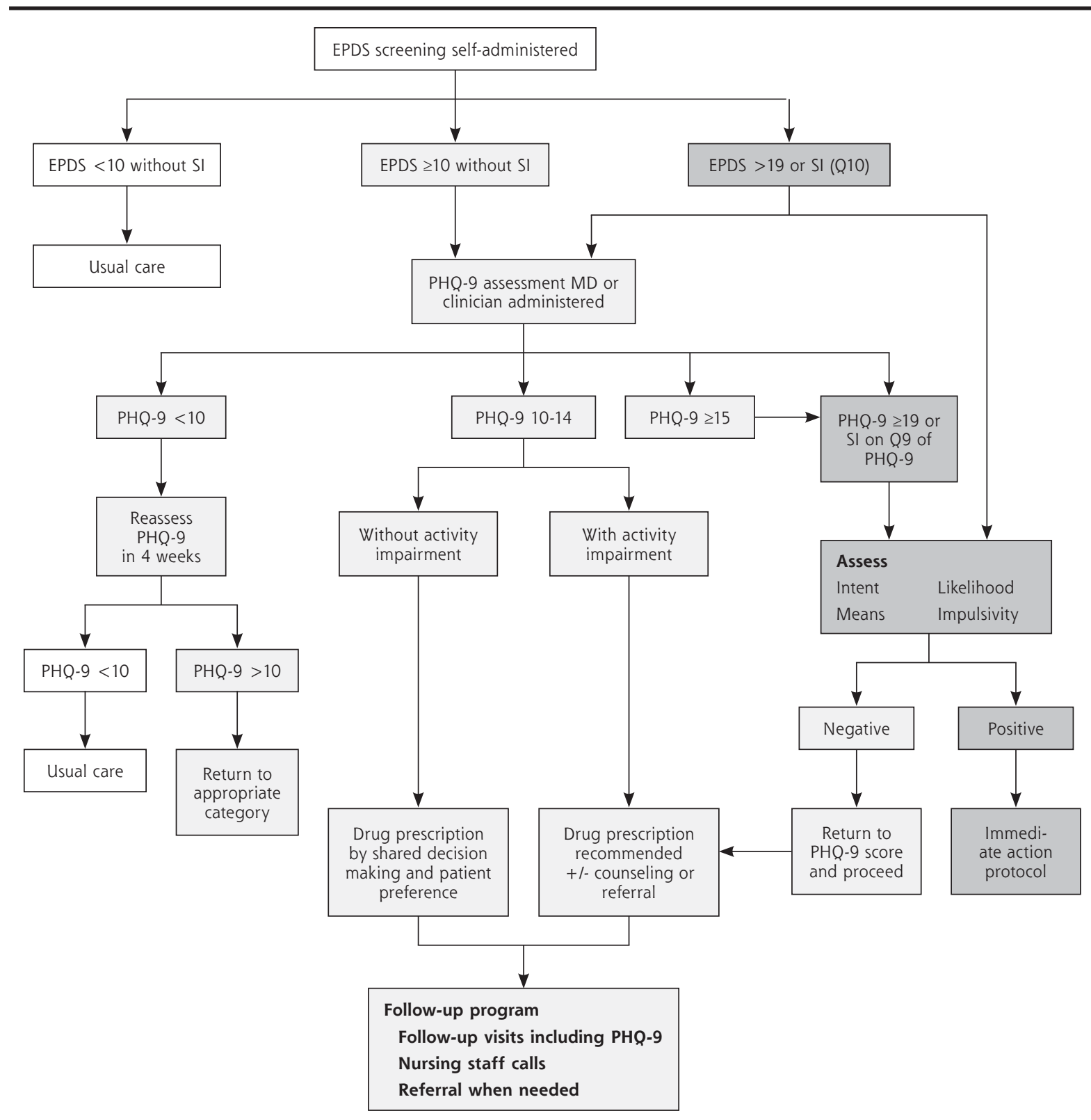

EPDS = Edinburgh Postnatal Depression Scale; $\mathrm{MD}=$ physician; PHQ-9 = 9-item Patient Health Questionnaire; $\mathrm{Q}=$ question; $\mathrm{R}=$ prescription medication; $\mathrm{SI}=$ suicidal ideation.

Notes: EPDS is scored on a range from 0 to 30, in which higher scores indicate possible depression. PHQ-9 is scored on a range from 0 to 27 , in which higher scores indicate more depressive symptoms. SI defined as EDPS score >19 and reply to question 10 (self-harm) was "sometimes" or "yes"; and PHQ-9 score $\geq 19$ and question 9 (better off dead) reply was more than "not at all."

White: women without suggestion of postpartum depression (normal EPDS).

Light gray: women at with high risk of postpartum depression and then with diagnosed postpartum depression.

Dark gray: women requiring assessment for suicidal ideation.

frequent thoughts of self-harm (EPDS) ${ }^{24}$ or being better off dead (PHQ-9) ${ }^{25}$ were recorded on a returned questionnaire. Although necessary for patient safety, these actions may have increased awareness of problems among usual-care women that would potentially bias our outcomes toward the null hypothesis. There were no completed suicides during the study period. Data on depression, dyad satisfaction, and maternal anxiety were self-reported. Data for calculating rates of postpartum depression diagnoses, therapy initia- 
tion, and referrals were obtained from medical record review. Copies of all enrolled women's medical records were sent to the central site and abstracted by 3 trained and experienced nurse abstractors; interrater reliability was assessed bimonthly. ${ }^{26}$

\section{Site Training}

A lead physician and nursing staff person were selected by each site. Those 2 individuals attended a training session held in Dallas, Texas. Human subjects training, general study procedures, such as completing and faxing to the central site informed consent, enrollment logs, and distribution of the initial survey packets, were completed with all sites together. The sites were then told their randomization status and separated by intervention and control sites. Control sites practiced informed consent and worked to develop a site-specific implementation plan. The intervention sites spent an additional half-day on general information pertaining to postpartum depression, on screening and diagnosis, as well as training and practice of nursing telephone calls, and on scoring and using PHQ-9 in case studies. All sites were given a prepared set of slides that shortened the training materials. The control sites were given a 1-hour program they presented to all clinicians and other staff members of their practices. The prepared slides for the intervention practices required 2 sessions, 1 hour each, with a refresher session 6 weeks later. Central study staff was on the telephone during all of the presentations within the study sites to support and answer questions.

\section{Data Analysis}

The primary outcome was a 5-point or greater drop in PHQ-9 score from baseline to 6 or 12 months' postpartum, which was considered to be indicative of a clinical improvement or response to therapy. ${ }^{27}$ Mean PHQ-9 scores were also calculated, but no references for a minimally significant difference were found. Secondary outcomes were the changes from baseline to 12 months' postpartum in parenting stress using the Parenting Stress Inventory (PSI, scored on a range from 36 to 180 , where higher scores indicated greater stress) ${ }^{28}$ and relationship satisfaction using the Dyad Adult Satisfaction short form (DAS-6, scored on a range from 0 to 65 , where higher scores indicate greater partner satisfaction). ${ }^{29}$ These instruments were also included in the survey packet of questionnaires at baseline, 6-months, and 12-months.

Practice change effects were tested with generalized linear mixed effect models, with a random mean term for the clinic, using the S-PLUS statistics package (TIBCO Software, Inc). A woman was classified as receiving the intervention if the clinic was offering the intervention at the time of her enrollment. Our data analysis was completed on the women who enrolled and returned 1 or more of the survey questionnaires. The characteristics selected for analysis, other than intervention, are factors reported in the literature to likely influence the outcomes. ${ }^{4,5,8,14}$ Both unadjusted odds ratios and odds ratios adjusted for all characteristics listed were calculated to determine the predictors of improvement in symptoms.

Secondary outcomes were the changes from baseline to 12 months' postpartum in PSI scores for parenting stress and DAS- 6 scores for relationship satisfaction.

Demographic and baseline characteristics of women who did and did not return survey questionnaires were compared using $\chi^{2}$ tests for categorical variables, and Wilcoxon rank-sum tests for numerical variables. Process outcomes and secondary outcomes (percentage showing low satisfaction on the DAS- 6 and high parenting stress on the PSI) were compared between usual-care and intervention groups using $\chi^{2}$ tests.

\section{Sample Size}

The power calculations for the random-effects model testing the screening intervention effect are based on 30 replications, with 4 additional practice-level factors (number of physicians, urban vs rural, residency, and single vs multispecialty), 4 additional patient-level factors (age, parity, previous history of depression, and income), and 4 physicians per practice (for the power estimate simulations, see Supplemental Table 1, available at http://annfammed.org/content/10/4/320/ suppl/DC1). ${ }^{30-32}$

\section{RESULTS}

\section{Practice and Participant Characteristics}

A total of 33 practices were enrolled, and 28 completed the study (Figure 2). Demographics of the physicians and residents are shown in Table 1. Overall, 2,343 postpartum women aged 18 years and older were enrolled in 28 practices, with a mean number of 83 patients enrolled per site (range $=23-187$ ). Of this group, 1,897 adult women $(80.1 \%)$ returned 1 or more of the survey questionnaires and could be included in the analysis. Questionnaire return rates decreased from $77 \%$ at baseline and $68 \%$ at 6 months to $62 \%$ at 12 months' postpartum. The Spanish language informed consent and questionnaires were used by $5.2 \%$ of the enrolled women.

Demographic and other important clinical characteristics of the enrolled women are enumerated in Table 2. The women in the usual-care and intervention practices differed in 3 important ways: the intervention women were poorer, less educated, and less likely to be married. All of these variables have 


\section{Figure 2. TRIPPD Consort diagram.}

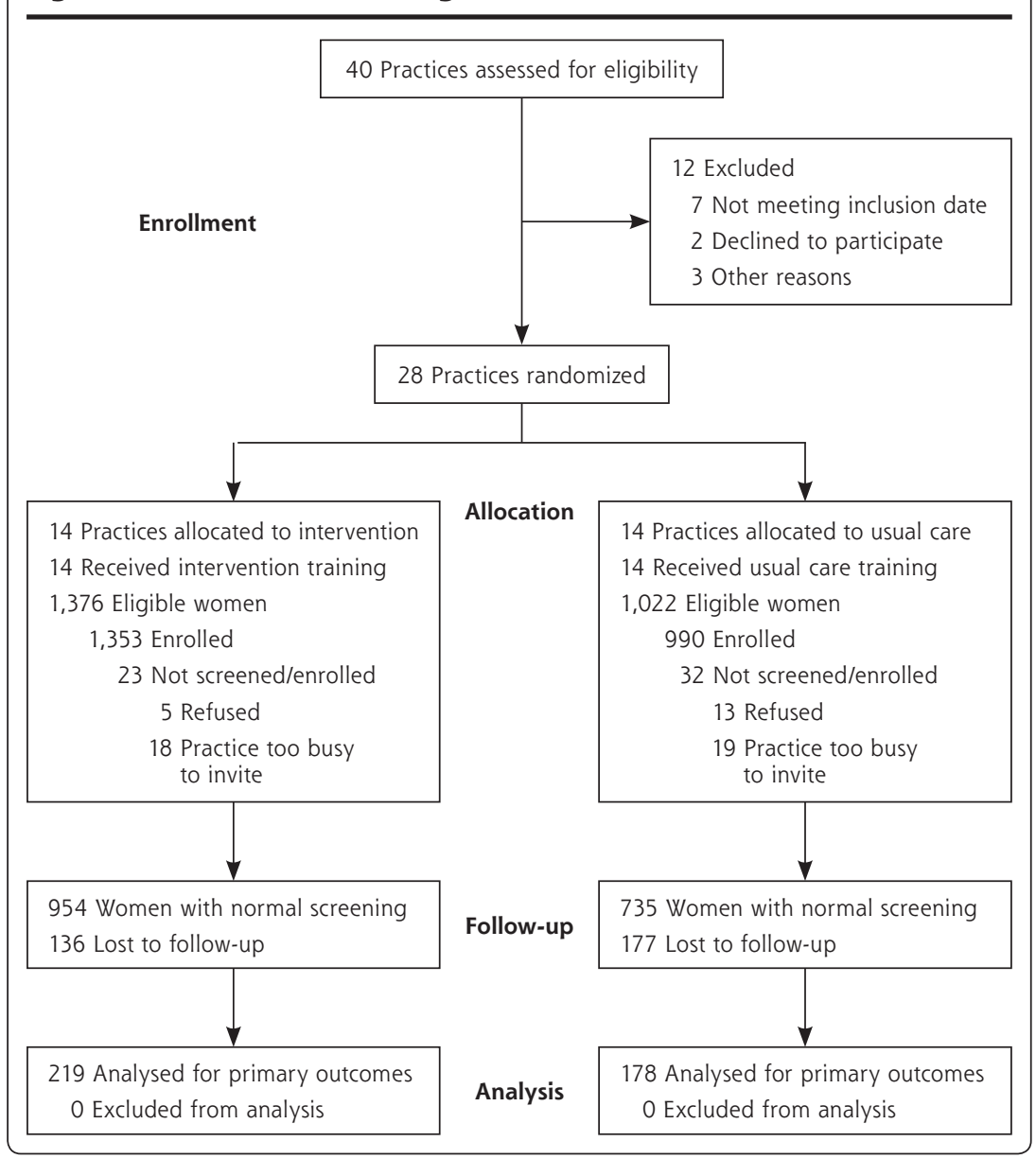

\section{Outcomes-Process}

Outcomes

Diagnosis, therapy initiation, and, although uncommon, referrals for psychiatric care for postpartum depression were significantly more likely among the intervention women (Tables 3). Four intervention women and 2 usual-care women received a new diagnosis of a complex mental health condition, such as bipolar disorder or schizophrenia.

The intervention tools recommended that nursing staff (usually nursing assistants) initiate followup telephone calls beginning at 1 to 2 weeks after the diagnosis of postpartum depression. Of the 287 intervention women diagnosed with depression, $250(87 \%)$ received 1 or more completed nursing support calls. Only 5 women had no attempted contacts because of a lack of nursing staff time. After a successful first call, however, only $22 \%$ of the women had 1 or more calls, with a mean of 2.3 calls (range $=2$ to 16). No woman in the usual-care group had any follow-up calls recorded in her medical record.

been associated in the medical literature with greater likelihood to develop and be more resistant to recovery from postpartum depression, thereby creating the potential for pushing our outcomes toward the null hypotheses. ${ }^{5,8,14}$ Overall, satisfaction with partner was high (DAS-6 score) in both intervention and usual-care groups at baseline. Maternal parenting stress (PSI score) was high at baseline but not different between groups

\section{Baseline Depressive Symptom Levels}

Overall, 399 (29.5\%) of the intervention women and $255(25.8 \%)$ of the usual-care women reported depression symptoms requiring further evaluation (Table 2). PHQ-9 scores of 15 points or greater at baseline (considered consistent with moderate to severe major depressive disorder ${ }^{25}$ ) were not significantly different between the 2 groups: $5.1 \%(n=41)$ of usual-care women, and $5.6 \%(\mathrm{n}=61)$ of the intervention women $(P>$.30).
Table 1. Demographic Information of Enrolled Practices, $n=28$

\begin{tabular}{llll}
\hline Clinician Type & Physicians & Residents & $\begin{array}{c}\text { Nonphysician } \\
\text { Clinicians }\end{array}$ \\
\hline Practice clinicians, mean (range), No. & $4(2-10)$ & $15(12-24)$ & $0.5(0-4)$ \\
Mean age, y (range) & $46(28-69)$ & $31(27$ to 47$)$ & $35(24-57)$ \\
Years in practice (including residency), & $21(1-41)$ & $2(1-3)$ & $8(1-6)$ \\
$\begin{array}{l}\text { No. (range) } \\
\text { Women, \% }\end{array}$ & 34 & 56 & 80 \\
\hline
\end{tabular}

Of the women with a diagnosis of postpartum depression, $16.9 \%$ lost their health insurance at 6 to 8 weeks' postpartum $(16.1 \%$ in intervention and $18.5 \%$ in usual care), making follow-up care for postpartum depression potentially less accessible.

\section{Outcomes-Depression Status}

Table 4 displays the results of the generalized linear mixed effects model for intervention status and patient factors predicting improved outcomes at 6 and 12 months' postpartum. Although depression outcomes differences did not reach our preset level of statisti- 
Table 2. Demographic Characteristics of Enrolled Women

\begin{tabular}{|c|c|c|c|c|}
\hline Characteristic & $\begin{array}{l}\text { All Usual-Care } \\
\text { Women } \\
(n=990)\end{array}$ & $\begin{array}{c}\text { All Intervention } \\
\text { Women } \\
(n=1,353)\end{array}$ & $\begin{array}{l}\text { Usual-Care Women } \\
\text { With Elevated } \\
\text { Depression Score }^{a} \\
(n=255)\end{array}$ & $\begin{array}{l}\text { Intervention Women } \\
\text { With Elevated } \\
\text { Depression Score } \\
(n=399)\end{array}$ \\
\hline Age, mean y (SD) & $26.7(5.6)$ & $26.1(5.4)$ & $26.8(5.7)$ & $25.6(5.2)$ \\
\hline Married, \% & 60 & 50 & 49 & 37 \\
\hline Living with partner, \% & 78 & 74 & 72 & 67 \\
\hline At least one other adult in household, \% & 90 & 87 & 86 & 81 \\
\hline Race: black, \% & 18 & 18 & 21 & 21 \\
\hline Ethnicity: Hispanic, \% & 14 & 18 & 13 & 19 \\
\hline Employed outside of home, \% & 45 & 48 & 42 & 43 \\
\hline Education > high school, \% & 56 & 49 & 50 & 43 \\
\hline Income $>\$ 50,000, \%$ & 40 & 35 & 33 & 24 \\
\hline Primiparous, \% & 37 & 38 & 34 & 38 \\
\hline History of depression, \% & 32 & 29 & 56 & 46 \\
\hline Uninsured at 1st postpartum visit, \% & 8 & 5 & 9 & 4 \\
\hline Uninsured at 2 months postpartum, \% & 42 & 33 & 35 & 23 \\
\hline
\end{tabular}

cal significance at 6 months, both the direction and strength of the association $(P=.07)$ lend support to the positive impact of the intervention seen at 12 months. The odds ratio for a 5-point drop in PHQ-9 between baseline and 12 months was 1.8 (95\% CI, 1.12.9) $(P=.001)$. The intraclass correlation coefficient for the 12-month change in PHQ-9 score, estimated from the variance components computed in S-PLUS, was 0.037 .

\section{Table 3. Characteristics of Women With Elevated Edinburgh Postnatal Depression Scale (EPDS) Scores $(\geq 10)$}

\begin{tabular}{|c|c|c|c|}
\hline Characteristic & $\begin{array}{l}\text { Usual Care } \\
(n=233) \\
\text { No. }(\%)\end{array}$ & $\begin{array}{c}\text { Intervention } \\
\text { (n= }=322) \\
\text { No. }(\%)\end{array}$ & $\begin{array}{c}P \\
\text { Value }\end{array}$ \\
\hline Received postpartum depression diagnosis ${ }^{a}$ & $78(41)$ & $194(66)$ & .0001 \\
\hline \multicolumn{4}{|l|}{ Elevated parenting stress (PSI score $>74)^{a}$} \\
\hline Baseline & $196(89)$ & $187(81)$ & .38 \\
\hline 12 Months' postpartumb & $117(74)$ & $128(72)$ & .82 \\
\hline \multicolumn{4}{|l|}{$\begin{array}{l}\text { Low partner satisfaction (DAS- } 6 \text { score } \\
\text { in bottom } 10 \% \text { ) }\end{array}$} \\
\hline Baseline & $3(2)$ & $3(2)$ & .71 \\
\hline 12 Months' postpartum & $6(5)$ & $2(2)$ & .30 \\
\hline \multicolumn{4}{|l|}{$\begin{array}{l}\text { Treatment of women with postpartum } \\
\text { depression diagnosis }\end{array}$} \\
\hline Medication & $67(35)$ & $169(56)$ & $<.0001$ \\
\hline Counseling & $20(11)$ & $54(20)$ & .02 \\
\hline Medication plus counseling & $70(37)$ & $176(60)$ & $<.0001$ \\
\hline \multicolumn{4}{|c|}{$\begin{array}{l}\text { DAS- } 6 \text { = Dyad Adult Satisfaction short form; PHQ-9 = 9-item Patient Health Questionnaire; PSI = Parenting } \\
\text { Stress Inventory. }\end{array}$} \\
\hline \multicolumn{4}{|c|}{ a According to PHQ-9 scores and clinician assessment. } \\
\hline
\end{tabular}

The only factors that had a significant impact on outcomes were a diagnosis of postpartum depression and elevated PSI scores. The diagnosis of postpartum depression was associated with improved outcomes, whereas the elevated PSI was associated with failure to improve outcomes. Of note is the negative association with high maternal parental stress and improvement in depression in both the intervention and usual-care women.

Univariate logistic regression models for the intervention and receiving a physician-reported diagnosis of postpartum depression showed that each factor was separately predictive of improvement ( $P=.01$ and .02 , respectively). A 2 -factor model that included intervention group and receiving a diagnosis of depression showed that both factors remained significant $(P=.045$ and .03 , respectively), indicating that the intervention had an association with improvement that was additive to the effect of increasing the rate of diagnosis of postpartum depression (data not shown).

\section{Secondary Outcomes}

We found no relationship between changes in the PSI or the DAS-6 scores and the intervention from baseline to 12 months. The rates 


\section{Table 4. Characteristics That Predict Improved Outcomes ( $\geq 5$-point Drop in PHQ-9 Score) at 12 Months, Odds Ratios From Logistic Regression (GLME)}

\begin{tabular}{|c|c|c|c|c|}
\hline \multirow[b]{2}{*}{ Characteristic } & \multicolumn{2}{|c|}{$\begin{array}{l}\text { Improved PHQ-9 } \\
\text { Score in Women With } \\
\text { Initial Elevated } \\
\text { Depression Scores }\end{array}$} & \multirow[b]{2}{*}{$\begin{array}{l}\text { Unadjusted OR } \\
(95 \% \mathrm{Cl})\end{array}$} & \multirow[b]{2}{*}{$\begin{array}{c}\text { Adjusted }^{a} \text { OR } \\
(95 \% \mathrm{Cl})\end{array}$} \\
\hline & $\begin{array}{c}\text { Usual Care } \\
\text { No. (\%) }\end{array}$ & $\begin{array}{l}\text { Intervention } \\
\text { No. (\%) }\end{array}$ & & \\
\hline Total & $60(35)$ & $98(45)$ & $1.82(1.14-2.91)^{b}$ & $1.74(1.05-2.86)^{b}$ \\
\hline \multicolumn{5}{|c|}{$\begin{array}{l}\text { Postpartum depres- } \\
\text { sion diagnosed }\end{array}$} \\
\hline Yes & $25(44)$ & $51(48)$ & $1.67(1.08-2.59)$ & $2.05(1.25-3.34)$ \\
\hline No & $24(27)$ & $37(41)$ & & \\
\hline \multicolumn{5}{|l|}{$\begin{array}{l}\text { History of } \\
\text { depression }\end{array}$} \\
\hline Yes & $33(33)$ & $40(41)$ & $0.69(0.46-1.04)$ & $0.79(0.51-1.23)$ \\
\hline No & $27(38)$ & $58(48)$ & & \\
\hline \multicolumn{5}{|l|}{ Married } \\
\hline Yes & $33(37)$ & $44(50)$ & $1.33(0.86-2.05)$ & $1.38(0.82-2.31)$ \\
\hline No & 27 (33) & $54(29)$ & & \\
\hline \multicolumn{5}{|l|}{ Income $>\$ 50,000$} \\
\hline Yes & $26(37)$ & $24(40)$ & $0.89(0.56-1.40)$ & $0.71(0.40-1.23)$ \\
\hline No & $33(35)$ & $70(46)$ & & \\
\hline \multicolumn{5}{|l|}{ Age $>25$ years } \\
\hline Yes & $38(36)$ & 49 (42) & $0.92(0.61-1.39)$ & $0.91(0.57-1.47)$ \\
\hline No & $22(33)$ & $49(48)$ & & \\
\hline \multicolumn{5}{|l|}{ Elevated PSI score } \\
\hline Yes & $41(33)$ & $58(39)$ & $0.51(0.33-0.80)^{c}$ & $0.52(0.33-0.84)$ \\
\hline No & $19(40)$ & $40(61)$ & & \\
\hline \multicolumn{5}{|l|}{$\begin{array}{l}\text { Education more } \\
\text { than high school }\end{array}$} \\
\hline Yes & $32(37)$ & $48(48)$ & $1.23(0.81-1.87)$ & $1.03(0.63-1.69)$ \\
\hline No & $28(33)$ & $50(42)$ & & \\
\hline
\end{tabular}

GLME = generalized linear mixed effects; OR = odds ratio; PHQ-9 = 9-item Patient Health Questionnaire; PSI = Parenting Stress Inventory

aR is calculated adjusting for all other variables in the table.

b Significant effect for intervention.

' Significant negative effect of high PSI score.

\section{Table 5. Characteristics of Women Initially Positive for Postpartum Depression Who Returned and Did Not Return Questionnaires at 12 Months' Postpartum}

\begin{tabular}{|c|c|c|c|c|}
\hline \multirow[b]{2}{*}{ Characteristic } & \multicolumn{2}{|c|}{ Usual Care, \% } & \multicolumn{2}{|c|}{ Intervention, \%a } \\
\hline & $\begin{array}{l}\text { Returned } \\
\text { Questionnaires } \\
(n=173)\end{array}$ & $\begin{array}{l}\text { Did Not Return } \\
\text { Questionnaires } \\
\quad(n=82)\end{array}$ & $\begin{array}{l}\text { Returned } \\
\text { Questionnaires } \\
(n=235)\end{array}$ & $\begin{array}{l}\text { Did Not Return } \\
\text { Questionnaires } \\
\quad(n=166)\end{array}$ \\
\hline Not married & 48 & 58 & 60 & 72 \\
\hline $\begin{array}{l}\text { History of } \\
\text { depression }\end{array}$ & 58 & 52 & 43 & 53 \\
\hline $\begin{array}{l}\text { Income } \\
\quad<\$ 50,000\end{array}$ & $57^{b}$ & $89^{b}$ & 72 & 84 \\
\hline $\begin{array}{l}\text { Uninsured at } \\
2 \text { months' } \\
\text { postpartum }\end{array}$ & $29^{b}$ & $49^{b}$ & 22 & 24 \\
\hline \multicolumn{5}{|c|}{$\begin{array}{l}\text { a No statistically significant differences between women who did and did not return questionnaires at } 12 \text { months' } \\
\text { postpartum. } \\
\text { b Statistically significant differences, } P<.01 \text {. }\end{array}$} \\
\hline
\end{tabular}

of high parental anxiety (elevated PSI scores $>74$ ) were directly related to elevated PHQ-9 scores $(\geq 10)$ at baseline $(P=.0001)$ and occurred in $55 \%$ of usual-care women and $55 \%$ of intervention women. Low DAS- 6 scores suggesting partner dissatisfaction occurred in only $1 \%$ of both usual-care and intervention

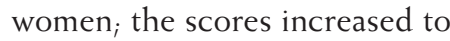
$2 \%$ in usual-care women and remained unchanged in intervention women at 12 months' postpartum $(P=.82)$. Twelve percent of the women stated they had no ongoing relationships for which they could assess dyad satisfaction.

\section{Women Who Returned the 12-Month Questionnaires vs Women Who Did Not}

We compared women who were included in the analysis of outcomes at 12 months' postpartum with those who did not return the follow-up questionnaires at 12 months' postpartum. Table 5 shows no statistically significant difference between women in the intervention group who were included in the analysis and those who did not return the 12-month questionnaires. Women in the usual-care group who did not return the 12-month questionnaires, however, were more likely to be poor and uninsured postpartum. The impact of these differences is unknown.

\section{DISCUSSION}

TRIPPD is the first large US based effectiveness study of screening and follow-up care for postpartum depression that has shown any improvement in maternal outcomes at 12 months. The study was based in 
real-world primary care practices, and most of the postpartum depression care was delivered within the primary care practices. Rates of diagnosis, treatment initiation, and referral for psychiatric evaluation were all higher in the intervention group, pointing to an effect of the program in raising awareness. The independent statistical significance of both receiving a diagnosis and being part of the intervention group highlights the importance of programs that go beyond just universal postpartum depression screening and initial diagnosis.

The rates of improvement among the intervention group are similar to those seen in many studies of adult depression outside the postpartum period where the primary therapy is antidepressant medications. ${ }^{1}$ In studies of adult depression, statistically significant improvement is often seen by 6 months. Little information is available, however, on the natural history of postpartum depression, and further research is required. It is possible that the additional burden of new parenting may delay response to therapy, especially in view of the moderately high levels of parental anxiety reported by the study women.

The TRIPPD program differs from similar programs that have reported no impact on maternal outcomes in 2 major aspects-most follow-up evaluation and postpartum depression care was provided within the primary care practices, and SCID evaluation was not used to diagnose postpartum depression. . $^{14,33-35}$ Gjerdingen et al clearly stated the problems they experienced in referring postpartum women from primary care sites to mental health practices for SCID assessment and diagnosis even when management was returned to the primary care site. ${ }^{36}$

In a broadly implemented program of screening and follow-up in Australia, only about $50 \%$ of women had even the initial step of postpartum depression screening. ${ }^{11,15}$ Outcomes were not improved. ${ }^{14,37}$ In the Netherlands a study of routine completed postpartum depression screening and intervention by a visiting nurse showed modest early improvement but had no lasting 5 -year benefits. ${ }^{35}$

In the United States, the Healthy Start program enrolled low-income women at the site of obstetrical care or through community awareness; women with elevated screening scores were referred to a different site for SCID evaluation. Outcomes were negative, and follow-up rates for mental health assessment were very low. ${ }^{14}$ Gjerdingen et al found similar problems in her study of stepped care for postpartum depression. Many women could not be reached for their telephone-based SCID assessment. In analyzing the problems with this approach, the authors reported that they considered referral for SCID to have introduced a large and uncorrectable bias in any outcomes attained. ${ }^{33}$
During the past 10 years, the only other study to show improved outcomes of postpartum depression screening and management was a relatively small study in the United Kingdom (UK). The UK study used visiting nurses specially trained to provide postpartum depression screening and a type of short-term cognitive behavioral therapy. ${ }^{39}$ In Finland a small preliminary study did not report outcomes but found that, with additional training, on-site nurses could provide about two-thirds of the nonmedication care that was provided to about one-half of the women-overall about $34 \%$ of care. ${ }^{40}$ Neither of these studies assessed the ability of primary care physicians, with additional training, to provide medication therapy and monitoring for postpartum depression.

TRIPPD was designed to remove the need for most women to seek evaluation and mental health care outside the primary care practice. Women have specifically reported a desire not to leave their usual practice for mental health services. ${ }^{41}$ TRIPPD study results support these findings. Tools (see the Supplemental Appendix) can facilitate primary care based treatment and follow-up. ${ }^{42-44}$

Retaining most postpartum depression care within the primary care practice increased the work required of these practices. The fidelity of the practices to the recommended practice changes was modest, with only 1 to 2 nursing staff support telephone calls to most women, and an average of only 1 to 2 follow-up visits after therapy initiation. Nurses reported that although they believe the support calls were important, they had little time to make additional follow-up calls; in addition, as time from delivery progressed, more women returned to work and could not be reached during usual office hours. ${ }^{45}$ Telephone calls often required 3 or more attempts. The addition of payments for care coordination promised under health care reform may help overcome these barriers to follow-up care.

Because of differences in the state's age of consent, only women aged 18 years and older were enrolled; therefore, the generalizability of this program to adolescent mothers is unknown. The practices that participated in this study were or became part of a practice-based research network, suggesting they may be more interested in embracing practice change than other US practices. Several studies of practice-based research network (PBRN) practices, however, have shown similarities rather than differences between PBRN practices and other family medicine practices in the United States. ${ }^{22}$ We did have 38\% loss to followup at 12 months, but this study's response rates were comparable with or higher than in many effectiveness studies. The differences between those who did and did not return the 12 -month questionnaires in the 
usual-care group might suggest that those with adverse outcomes were less likely to respond. No significant differences were seen in the intervention group. This finding might suggest that overall the usual-care group might have had worse outcomes than the women who returned the questionnaires, making the potential value of the intervention even higher if all had responded.

In these family medicine practices, universal postpartum depression screening accompanied by on-site depression management improved maternal outcomes at 12 months' postpartum. Not only did screening increase the number of women with a diagnosis of postpartum depression, ${ }^{8-10,11}$ it also improved the outcomes in those women whose postpartum depression was diagnosed. Considering the multiple and long-lasting adverse effects of postpartum depression, these findings appear to warrant dissemination efforts and continued evaluation of outcomes of TRIPPD-like programs based in family medicine offices that have minimal requirements for referrals to outside mental health services. Efforts to enhance training or include other clinicians (such as on-site mental health clinicians) to improve program fidelity should be part of the next steps.

To read or post commentaries in response to this article, see it online at http://www.annfammed.org/content/10/4/320.

Key words: practice-based research; postpartum depression; comparative effectiveness research; screening; follow-up studies; translational medical research; practice tools

Submitted January 24, 2012; submitted, revised April 10, 2012; accepted April 16, 2012.

Funding support: Funded by the Agency for HealthCare Research and Quality: R01-HS40471).

The TRIPPD team of practices: St. Vincent's East Family Medicine, Birmingham, Alabama; UCSD Family Medicine, San Diego, California; Salud Family Health Center-Sterling, Sterling, Colorado; Southwest Memorial Primary Care, Cortez, Colorado; Heartland Clinic at Carver, Peoria, Illinois; Methodist Family Medical Center, Peoria, Illinois; St. Vincent Family Medicine Residency Program, Indianapolis, Indiana; Bates, Miller \& Sims, Stanford, Kentucky; Masonic Medical Center St. John Hospital \& Medical Center, St Clair Shores, Michigan; Northwest Family Physicians, Minneapolis, Minnesota; Research Family Medicine Residency Program, Kansas City, Missouri; Cornerstone Family Health Care, Ardmore, Oklahoma; University of Oklahoma Family Medical Center, Oklahoma City, Oklahoma; South Tulsa Maternity \& Pediatric Associates, Tulsa, Oklahoma; Washington Hospital Family Practice Residency, Washington, Pennsylvania; Lancaster General Hospital, Lancaster, Pennsylvania; Lancaster General Family \& Maternity Care, Lancaster, Pennsylvania; Family Medicine of Albemarle, Charlottesville, Virginia; Deerfield Valley Health Center, Wilmington, Vermont; Aspirus Kronenwetter Clinic, Kronenwetter, Wisconsin; La Crosse-Mayo Family Medicine Residency, La Crosse, Wisconsin; Mercy/Mayo Family Practice Residency Program, Des Moines, lowa; Prairie Family Medicine and Obstetrics, Ltd, Forrest, Illinois; RiverStone Health, Billings, Montana; Rocky Mountain Clinic, Butte, Montana; Partners in Family Health Care, Pawtucket, Rhode Island; Baylor Family Medicine Residency at Garland, Garland, Texas;
Valley Baptist Family Practice Residency, Harlingen, Texas; Utah County Medical Associates, Payson, Utah; Maricopa County Clinic, Phoenix, Arizona; G.A. Carmichael Family Health Center, Canton, Mississippi.

Acknowledgments: The research team appreciates the very detailed and helpful critical review of this manuscript and sharing of expertise provided by Dr Ardis L. Olson and the support of Dawn Littlefield in preparation of this manuscript.

\section{References}

1. National Research Council and Institute of Medicine. Depression in Parents, Parenting, and Children: Opportunities to Improve Identification, Treatment, and Prevention. Committee on Depression, Parenting Practices, and the Healthy Development of Children. Board on Children, Youth, and Families. Division of Behavioral and Social Sciences and Education. Washington, DC: The National Academies Press; 2009.

2. Field T. Prenatal depression effects on early development: a review. Infant Behav Dev. 2011;34(1):1-14.

3. Feldman R, Granat A, Pariente C, Kanety H, Kuint J, Gilboa-Schechtman E. Maternal depression and anxiety across the postpartum year and infant social engagement, fear regulation, and stress reactivity. J Am Acad Child Adolesc Psychiatry. 2009;48(9):919-927.

4. Georgiopoulos AM, Bryan TL, Yawn BP, Houston MS, Rummans TA, Therneau TM. Population-based screening for postpartum depression. Obstet Gynecol. 1999;93(5 Pt 1):653-657.

5. Bryan TL, Georgiopoulos AM, Harms RW, Huxsahl JE, Larson DR, Yawn BP. Incidence of postpartum depression in Olmsted County, Minnesota. A population-based, retrospective study. J Reprod Med. 1999;44(4):351-358

6. Avan B, Richter LM, Ramchandani PG, Norris SA, Stein A. Maternal postnatal depression and children's growth and behaviour during the early years of life: exploring the interaction between physical and mental health. Arch Dis Child. 2010;95(9):690-695.

7. Murray L, Arteche A, Fearon P, Halligan S, Croudace T, Cooper P. The effects of maternal postnatal depression and child sex on academic performance at age 16 years: a developmental approach. J Child Psychol Psychiatry. 2010;51(10):1150-1159.

8. Georgiopoulos AM, Bryan TL, Wollan P, Yawn BP. Routine screening for postpartum depression. J Fam Pract. 2001;50(2):117-122.

9. Paulden M, Palmer S, Hewitt C, Gilbody S. Screening for postnatal depression in primary care: cost effectiveness analysis. BMJ. 2009;339:b5203.

10. Sheeder J, Kabir K, Stafford B. Screening for postpartum depression at well-child visits: is once enough during the first 6 months of life? Pediatrics. 2009;123(6):e982-e988.

11. Armstrong S, Small R. Screening for postnatal depression: not a simple task. Aust N Z J Public Health. 2007;31(1):57-61.

12. Mishina H, Takayama JI. Screening for maternal depression in primary care pediatrics. Curr Opin Pediatr. 2009;21(6):789-793.

13. Horowitz JA, Murphy CA, Gregory KE, Wojcik J. Best practices: community-based postpartum depression screening: results from the CARE study. Psychiatr Serv. 2009;60(11):1432-1434.

14. Yonkers KA, Smith MV, Lin H, Howell HB, Shao L, Rosenheck RA. Depression screening of perinatal women: an evaluation of the healthy start depression initiative. Psychiatr Serv. 2009;60(3):322-328.

15. Buist A, Ellwood D, Brooks J, et al. National program for depression associated with childbirth: the Australian experience. Best Pract Res Clin Obstet Gynaecol. 2007;21(2):193-206.

16. Bennett IM, Coco A, Coyne JC, et al. Efficiency of a two-item prescreen to reduce the burden of depression screening in pregnancy and postpartum: an IMPLICIT network study. J Am Board Fam Med. 2008;21(4):317-325. 
17. Hewitt CE, Gilbody SM. Is it clinically and cost effective to screen for postnatal depression: a systematic review of controlled clinical trials and economic evidence. BJOG. 2009;116(8):1019-1027.

18. American College of Obstetricians and Gynecologists. Committee on Obstetric Practice. Committee opinion no. 453: Screening for depression during and after pregnancy. Obstet Gynecol. 2010;115 (2 Pt 1):394-395.

19. Recommendations of the U.S. Preventive Services Task Force. The Guide to Clinical Preventive Services 2007. The Agency for Healthcare Research, and Quality (AHRQ). Pub No. 07-05100. September 2007. http://www.ahrq.gov/clinic/uspstf/uspstopics.htm. Accessed April 5, 2012

20. NICE guidelines for perinatal mental health. (includes PPD screening) http://www.nice.org.uk/nicemedia/live/11004/30433/30433. pdf. Accessed April 5, 2012

21. Scottish Intercollegiate Guideline Network for postpartum mental health. http://www.sign.ac.uk/guidelines/fulltext/60/section2.html. Accessed April 5, 2012

22. Galliher JM, Bonham AJ, Dickinson LM, Staton EW, Pace WD. Representativeness of PBRN physician practice patterns and related beliefs: the case of the AAFP National Research Network. Ann Fam Med. 2009;7(6):547-554.

23. Lee DT, Yip AS, Chiu HF, Chung TK. Screening for postnatal depression using the double-test strategy. Psychosom Med. 2000;62(2): 258-263.

24. Cox J, Holden J, Sagovsky R. Detection of postnatal depression. Development of the 10-item Edinburgh Postnatal Depression Scale. Br J Psychiatry. 1987;150:782-786.

25. Spitzer RL, Kroenke K, Williams JB. Validation and utility of a selfreport version of PRIME-MD: the PHQ primary care study. Primary Care Evaluation of Mental Disorders. Patient Health Questionnaire. JAMA. 1999;282(18):1737-1744

26. Yawn BP, Wollan P. Interrater reliability: completing the methods description in medical records review studies. Am J Epidemiol. 2005; 161(10):974-977.

27. Löwe B, Kroenke K, Herzog W, Gräfe K. Measuring depression outcome with a brief self-report instrument: sensitivity to change of the Patient Health Questionnaire (PHQ-9). J Affect Disord. 2004;81(1):61-66.

28. Abidin RR. Parenting stress index: a measure of the parent-child system. In Zalaquett CP, Wood R, eds. Evaluating Stress: A Book of Resources. Lantham, MD: Scarecrow Press, Inc; 1997:277-291.

29. Spanier GB. The measurement of marital quality. J Sex Marital Ther. 1979;5(3):288-300.

30. Wickberg B, Hwang CP. Screening for postnatal depression in a population-based Swedish sample. Acta Psychiatr Scan 1997;95:62-66.

31. MacArthur C, Winter HR, Bick DE, Knowles $H$, Lilford R, Henderson $C$, et al. Effects of redesigned community postnatal care on womens' health 4 months after birth: a cluster randomised controlled trial. Lancet 2002;359:378-385.
32. Gunn J, Lumley J, Chondros P, Young D. Does an early postnatal check-up improve maternal health: results from a randomized trial in Australian general practice. Br J Obstet Gynaecol 1998;105(9):991-997.

33. Kozhimannil KB, Adams AS, Soumerai SB, Busch AB, Huskamp HA. New Jersey's efforts to improve postpartum depression care did not change treatment patterns for women on medicaid. Health Aff (Millwood). 2011;30(2):293-301.

34. Reay R, Matthey S, Ellwood D, Scott M. Long-term outcomes of participants in a perinatal depression early detection program. J Affect Disord. 2011;129(1-3):94-103.

35. Austin MP, Reilly N, Milgrom J, Barnett B. A national approach to perinatal mental health in Australia: exercising caution in the rollout of a public health initiative. Med J Aust. 2010;192(2):111.

36. Gjerdingen D, McGovern P, Center B. Problems with a diagnostic depression interview in a postpartum depression trial. J Am Board Fam Med. 2011;24(2):187-193.

37. Smith MV, Shao L, Howell H, Wang H, Poschman K, Yonkers KA. Success of mental health referral among pregnant and postpartum women with psychiatric distress. Gen Hosp Psychiatry. 2009;31(2): $155-162$.

38. Flynn HA, Henshaw E, O'Mahen H, Forman J. Patient perspectives on improving the depression referral processes in obstetrics settings: a qualitative study. Gen Hosp Psychiatry. 2010;32(1):9-16.

39. Kersten-Alvarez LE, Hosman CM, Riksen-Walraven JM, Van Doesum KT, Hoefnagels C. Long-term effects of a home-visiting intervention for depressed mothers and their infants. J Child Psychol Psychiatry. 2010;51(10):1160-1170

40. Segre LS, O'Hara MW, Arndt S, Beck CT. Nursing care for postpartum depression, part 1: do nurses think they should offer both screening and counseling? MCN Am J Matern Child Nurs. 2010;35(4): 220-225.

41. Kuosmanen L, Vuorilehto M, Kumpuniemi S, Melartin T. Post-nata depression screening and treatment in maternity and child health clinics. J Psychiatr Ment Health Nurs. 2010;17(6):554-557.

42. Sit DK, Flint C, Svidergol D, et al. Best practices: an emerging best practice model for perinatal depression care. Psychiatr Serv. 2009; 60(11):1429-1431

43. Katon WJ, Lin EH, Von Korff M, et al. Collaborative care for patients with depression and chronic illnesses. N Engl J Med. 2010; 363(27):2611-2620.

44. Dietrich AJ, Oxman TE, Williams JW Jr, et al. Re-engineering systems for the treatment of depression in primary care: cluster randomised controlled trial. BMJ. 2004;329(7466):602. Epub2004Sep2.

45. Yawn BP, Pace W, Dietrich A, et al. Practice benefit from participating in a practice-based research network study of postpartum depression: a national research network (NRN) report. J Am Board Fam Med. 2010;23(4):455-464. 